\title{
Elas no poder: economia solidária e participação feminina na feira da agriculura familiar da UFOPA
}

Women in power: solidary economy and female participation at the family agriculture fair in UFOPA

\author{
Zilda Joaquina Cohen Gama dos Santos ${ }^{1}$ \\ Giselle Alves Silva ${ }^{2}$ \\ Ana Carla dos Santos Evangelista ${ }^{3}$ \\ Breno Pinho de Sousa ${ }^{4}$
}

\begin{abstract}
Resumo:
Este trabalho tem como objetivo analisar a contribuição da Feira de Agricultura Familiar, uma iniciativa da Incubadora de Empreendimentos Solidários da UFOPA, para o fortalecimento do empoderamento feminino de suas produtoras. A pesquisa realizada pautou-se no aporte teórico da economia solidária, agricultura familiar e empoderamento feminino. Trata-se de um estudo de caso, que utilizou como metodologia a revisão bibliográfica, análise documental, e a coleta de dados primários e secundários. Os resultados obtidos possibilitaram identificar que a feira se constitui em uma ferramenta para construção do empoderamento feminino, sendo espaço de troca de experiências, conhecimentos e trocas econômicas que são pautados nas diretrizes da Economia Solidária. As principais conquistas das agricultoras relacionam-se ao aumento da renda mensal, a oportunidade de ter um espaço para comercializar, um novo canal de comunicação, o aumento da confiança e maior autonomia econômica.
\end{abstract}

Palavras-chaves: Empoderamento Feminino; Incubadora de Empreendimentos Solidários; Economia Solidária.

\begin{abstract}
:
This work aims to analyze the contribution of the Family Agriculture Fair, an initiative of the UFOPA Incubator for Solidarity Enterprises, to strengthen the female empowerment of its producers. The research carried out was based on the theoretical contribution of the solidarity economy, family farming and women's empowerment. This is a case study, which used as a methodology the bibliographic review, document analysis, and the collection of primary and secondary data. The results obtained made it possible to identify that the fair is a tool for the construction of female empowerment, being a space for exchanging experiences, knowledge and economic exchanges that are guided by the guidelines of the Solidarity Economy. The main achievements of farmers are related to the increase in monthly
\end{abstract}

\footnotetext{
1 Professora Adjunta III do curso de Ciências Econômicas da Universidade Federal do Oeste do Pará. E-mail: zilda.santos@ufopa.edu.br

2 Professora do curso de Gestão Pública e Desenvolvimento Regional da Universidade Federal do Oeste do Pará. Email: giselle.silva@ufopa.edu.br

3 Bacharel em Ciências Econômicas pela Universidade Federal dos Oeste do Pará. E-mail: anacarlaics@gmail.com

4 Graduando do curso de Ciências Econômicas da Universidade Federal do Oeste do Pará. E-mail: puruspinho@gmail.com
} 
income, the opportunity to have a space to sell, a new communication channel, increased confidence and greater economic autonomy

Keywords: Female Empowerment; Incubator for Solidarity Enterprises; Solidarity Economy

\author{
Introdução
}

No atual contexto global o imponente capitalismo é o modo de produção triunfante em grande parte dos países, assumindo uma perspectiva norteadora cada vez mais competitiva e individualista, mostrando através das desigualdades socioeconômicas o seu grande potencial centralizador e segregador. $\mathrm{Na}$ contramão desse panorama, surge a economia solidária como uma alternativa das camadas desfavorecidas na busca pela conquista de espaço nesse ambiente desigual, através de ações mais humanizadas, pensadas tanto para auferir meios de sobrevivência como também para fortalecer laços sociais e sentimentos de reciprocidade, igualdade e solidariedade, exercidos coletivamente.

Sendo assim, a economia solidária foge à regra da economia convencional que evita a separação entre o econômico, o social e o político. Segundo Aleixo (2019, p.32) a Economia Solidária é "(...) caracterizada como um conjunto de atividades econômicas cuja lógica é distinta da lógica do mercado (...), e organiza-se a partir de fatores humanos", participando de dinâmicas tanto rurais como urbanas.

No âmbito rural, foco deste estudo, têm-se as experiências na área da agricultura familiar, campo formado por uma diversidade de atores, em grande parte pequenos produtores. De acordo com a Lei $n^{\circ} 11.326$ de 24 de junho, 2006, a produção dessa agricultura é realizada pelos próprios membros da família. Em geral, esse tipo de agricultura consome parte do que produz e revende apenas o excedente da sua produção. As experiências dos empreendimentos solidários baseados na autogestão e cooperação permitem aos agricultores e agricultoras o acesso ao mercado direto sem a dependência de terceiros para comercializar, assim tendo contato direto com o público consumidor. Uma dessas experiências são as feiras livres que proporcionam a valorização dessa atividade sustentável e fortalecimento das redes de cooperação.

Nesse contexto da agricultura um elemento de destaque é o protagonismo das mulheres agricultoras, que no decorrer da história buscam por direitos básicos, reconhecimento e oportunidades, pois, por um longo tempo viveram imersas na relação de dominação do patriarcado. Atualmente, são vistas várias experiências de empreendimentos solidários de organizações de mulheres, através dos coletivos elas veem a oportunidade de ganhar espaço na sociedade e se empoderar individualmente e coletivamente.

Face ao exposto, o presente trabalho se debruçará em uma iniciativa da Incubadora de Empreendimentos Solidários -IES da Universidade Federal do Oeste do Pará - UFOPA, que corresponde a um projeto de extensão criado em 2013, cuja função é intermediar a construção da autogestão dos Empreendimentos Econômicos Solidários - EES constituídos por agricultores familiares rurais, seguindo os princípios da Economia Solidária (ES) - cooperação, solidariedade, autogestão e viabilidade social e econômica (Silva, 2019).

Uma das principais iniciativas da Incubadora no fomento à agricultura familiar e aos empreendimentos econômicos solidários, foi a criação em 2016 da Feira de Agricultura Familiar - FAF da Universidade Federal do Oeste do Pará, objeto de estudo deste artigo, que é composta de associações e movimentos de mulheres agricultoras, além de cooperativas com participação também do público masculino. 
Entre os anos de 2016 a 2019 a feira tem conquistado grande visibilidade na comunidade local, com acentuado protagonismo das agricultoras nesse processo. Face ao exposto, a presente pesquisa traz como questão norteadora: De que forma a Feira da Agricultura Familiar da UFOPA tem contribuído no empoderamento feminino das mulheres que comercializam na feira?

Para responder a essa questão de investigação, o presente estudo se propões a: a) Descrever as atividades da FAF-UFOPA a luz dos princípios da economia solidária; b) Apresentar o perfil socioeconômico das agricultoras da FAF-UFOPA; c) Relatar as principais conquistas e desafios descritos pelas agricultoras da feira com enfoque no empoderamento feminino.

A temática levantada justifica-se como relevante ao analisar as experiências de empreendimentos solidários que busquem valorizar o papel da mulher agricultora, com a finalidade de contribuir para ações mais efetivas tanto de produção científica quanto relacionada ao incentivo à política pública para subsidiar o empoderamento da agricultora e diminuir as desigualdades de gênero existentes na sociedade pela via da economia solidária.

A pesquisa realizada possui abordagem qualitativa, objetivo exploratório, tendo adotado como procedimentos: a pesquisa bibliográfica, pesquisa documental, entrevistas e pesquisa participante, posto que todos os autores deste artigo estão diretamente envolvidos no projeto da Incubadora e nas atividades da feira. Este empreendimento econômico solidário - FAF - é formada por 11 produtores, que estão divididos em 6 associações ou cooperativas, em todos esses empreendimentos tem-se a presença da figura feminina na liderança do negócio. No dia de aplicação dos questionários foram entrevistadas as nove produtoras que estavam na feira, representando $81 \%$ do público alvo cadastrado na FAF - UFOPA.

O trabalho está dividiu-se em cinco partes, além desta introdução, tem-se o referencial teórico sobre os pressupostos da Economia Solidária, perpassando por sua origem, seus conceitos e diretrizes e por fim seu atual panorama no país. No segundo tópico propõem-se uma discussão sobre a agricultura familiar, conceito e seus resultados no Brasil; seguindo para o empoderamento feminino, sua origem, significado e experiências. No quarto tópico apresentam-se os resultados obtidos na pesquisa de acordo com os objetivos estipulados inicialmente. Sendo que o primeiro corresponde a contextualização e resultados da FAF UFOPA, o segundo corresponde ao perfil socioeconômico da mulher agricultora e, por fim, as principais conquistas e avanços das agricultoras sobre o empoderamento e o último capítulo têm as considerações sobre a resolução da problemática e o alcance dos objetivos.

\section{Economia solidária, agricultura familiar e empoderamento feminino: bases teóricas}

Essa seção tem como objetivo apresentar e discutir as categorias teórico-analíticas fundamentais para a compreensão de como a Incubadora de Empreendimentos Econômicos Solidários da UFOPA, por meio de sua ação com a Feira da Agricultura Familiar, representa um espaço de empoderamento feminino para agricultoras familiares. Desse modo, primeiramente são apresentados os conceitos de Economia Solidária (ES), bem como um breve histórico de sua implementação como política pública no Brasil, em seguida discute-se a construção do conceito de agricultura familiar e por último apresenta-se os principais fundamentos da discussão em torno do empoderamento feminino.

\subsection{Economia Solidária: origem, conceito e política pública}


De acordo com Santos (2019) o surgimento da ES está atrelado a antigos pressupostos teóricos que moldaram a luta das classes contra a pauperização no século XIX na Europa. O socialismo utópico desenvolvido nesse período teve grande relevância na base ideológica da ES, com ênfase nos percussores da Economia e do socialismo como Henri de Saint-Simon (1760-1825), François Charles Fourier (17721837), Robert Owen (1771-1858), além de Pierre-Joseph Proudhon (1809-1865), um dos primeiros a argumentar sobre a importância das associações e cooperativismo dos trabalhadores para burlar os efeitos nocivos do capitalismo.

Singer (2002a) afirma que ao longo dos anos a ES não parou de se expandir pelo mundo, mas teve uma acentuada queda no período do pleno emprego, entre as décadas de 1940 e 1970, resultado da conquista de direitos trabalhistas, os quais geraram ao empregado condições satisfatórias para se viver em sociedade. Entretanto, a partir da década de $1970 \mathrm{com}$ a crise do Estado, o avanço do liberalismo e, consequentemente, a diminuição dos direitos sociais, disseminou-se no mundo altos níveis de desemprego, o que reanimou o movimento da ES.

No cenário internacional Jean-Louis Laville, sociólogo francês, foi o primeiro teórico a identificar na Europa uma forma diferente de atuar no modo de produção capitalista. Essa nova abordagem destacava aspectos de associativismo e cooperativismo como as primeiras características da economia solidária. Em meados da década de 1990, Laville buscou identificar e estudar esses empreendimentos de associativismo que vinham surgindo na França em decorrência do desemprego e da exclusão de classes, proporcionados pelos efeitos do modo de produção capitalista (Santos, 2019).

No Brasil o panorama das décadas de 1980 e 1990 era tanto econômico como socialmente precário, com altos índices de desemprego e desindustrialização. Esses aspectos contraditórios do capitalismo tornaram propício o surgimento do debate em torno dos pressupostos da ES no país (Singer, 2002a; Singer, 2002b).

Ressalta-se a importância das organizações sociais para o processo de amadurecimento da ES, principalmente com a assessoria e disseminação de informações, entre elas, cita-se as Organizações NãoGovernamentais (ONGs), os Sindicatos, o Movimento dos Sem Terra (MST) e a Igreja Católica por meio da Conferência Nacional dos Bispos do Brasil (CNBB). Essas organizações se fizeram ativas diante das questões sociais fragilizadas na época como a violência no campo e reforma agrária, o desinteresse do Estado com os assuntos ambientais, o aumento da pobreza e desemprego, entre outros fatores (Singer, 2002b).

Uma das primeiras experiências concretas de empreendimentos solidários foi o surgimento, em meados de 1991, da Associação Nacional de Trabalhadores e Empresas de Autogestão (ANTEAG) que se formou pela iniciativa de funcionários em virtude da falência de grandes empresas (Nagem; De Jesus, 2019)

Outras experiências nesse sentido foram as Incubadoras Tecnológicas de Cooperativas Populares (ITCP) formadas por cooperativas ou associações de pessoas auxiliadas pelas universidades. A incubação universitária constituía-se de assessoria de ES e jurídica, auxílio técnico para o desenvolvimento de atividades, e outros, gerando apoio aos componentes do empreendimento solidário para futuramente obterem bons resultados e se autogerirem (Singer, 2002b).

A partir de uma rede solidária que se forma na década de 1980-1990, o embrião da ES se fortalece e inicia sua articulação em âmbito nacional com fins de disseminar as experiências de empreendimentos e conseguir maiores condições para institucionalização dessa prática. Assim, no começo do século XXI surge o Fórum Brasileiro de Economia Solidária (FBES) que na sua Primeira Plenária realizada em 2002 definiu que:

A Economia Solidária se caracteriza por concepções e práticas fundadas em relações de colaboração solidária, inspiradas por valores culturais que colocam o ser humano na sua 
integralidade ética e lúdica e como sujeito e finalidade da atividade econômica, ambientalmente sustentável e socialmente justa, ao invés da acumulação privada do capital. Essa prática de produção, comercialização, finanças e consumo privilegia a autogestão, a cooperação, o desenvolvimento comunitário e humano, a satisfação das necessidades humanas, a justiça social, a igualdade de gênero, raça, etnia, acesso igualitário à informação, ao conhecimento e a segurança alimentar, preservação dos recursos naturais pelo manejo sustentável e responsabilidade com as gerações, presente e futuro, construindo uma nova forma de inclusão social com a participação de todos (MTE/SENAES, 2010, p. 32)

O Fórum continuou a acontecer nos anos subseqüentes e na III Plenária emergiu o conceito de ES:

A Economia Solidária representa práticas fundadas em relações de colaboração solidária, inspiradas por valores culturais que colocam o ser humano como sujeito e finalidade da atividade econômica, em vez da acumulação privada de riqueza em geral e de capital em particular (FBES, 2005, p.2)

Podem-se inferir características comuns entre esses conceitos, como a igualdade (aspectos econômicos e sociais), autogestão, cooperação, busca pelo bem-estar, além da preocupação com a preservação do meio ambiente. Contudo, observa-se também que ES possui um nível complexo de relações, sua atuação em rede permite seu funcionamento de forma diversa em cada empreendimento, de fato não se tem um padrão, mas sim construções sociais especializadas em virtude da prática social dos indivíduos e o culto aos valores não egoístas permeados pela reciprocidade.

Dessa forma, para França-Filho (2007) as atividades exercidas pelos empreendimentos solidários derivam de demandas reais no cotidiano do território, no qual houve impactos positivos das relações comerciais na dinâmica socioeconômica. Esse autor destacou três formas de organizações presentes na dinâmica da ES: Empreendimentos Econômicos Solidários (EES), Entidades de Apoio e Fomento (EAF) e por último as formas de auto-organização política.

De acordo com Cattani et al. (2009) os ESS, são:

O conceito de empreendimento econômico solidário compreende as diversas modalidades de organização econômica, originadas da livre associação de trabalhadores, nas quais a cooperação funciona como esteio de sua eficiência e viabilidade. Sua presença tem se verificado em setores da produção, prestação de serviços, comercialização e crédito (Cattani, et. al, 2009, p.181)

Conforme o conceito de Cattani et. al (2009) os EES podem atuar em diversas áreas do mercado, sua organização é baseada na cooperação do coletivo, sendo determinante para obter bons resultados. Nessa forma de organização, França Filho (2007) argumenta sobre a diversidade existente na composição, como cooperativas populares ou cooperativas de trabalho e produção, organizações de trabalhadores, bancos comunitários, etc. 
As EAF realizam fomento e/ou acompanhamento técnico dos empreendimentos solidários, sendo possuidoras de certa responsabilidade na autogestão do empreendimento até a total autonomia e sustentabilidade do empreendimento. Ressalta-se que as EAF's podem ser ONGs ou mesmo grupos de profissionais técnicos ligados a universidades ou núcleos de pesquisas.

Toda essa discussão em torno da ES iniciada na sociedade civil foi institucionalizada como política pública com a criação de uma Secretaria Nacional no Ministério do Trabalho e Emprego em 2003. De acordo com o levantamento de Silva (2018) o marco inicial nessa fase de incentivo a prática da ES foi à implementação do Programa Economia Solidária em Desenvolvimento (PESD) por meio do Plano Plurianual de 2004-2007 e sua continuação com o Programa Plurianual (PPA) de 2008-2011.

Apesar das várias ações e políticas priorizando a ES nesse período, a partir do ano de 2013, observa-se a descontinuidade dessas políticas na agenda governamental do país, de modo que esta passa a integrar uma linha multidimensional (formada por várias temáticas) denominada Desenvolvimento Regional, Territorial Sustentável e Economia Solidária (DRTSES), na qual vários ministérios são envolvidos (Silva, 2018).

Atualmente, de acordo com o Ministério da Cidadania o eixo ES passou a ser incluído a partir de 2019 na nova Secretaria Nacional de Inclusão Social e Produtiva Urbana (SENISP), cuja temática da ES se alia a diferentes linhas, não existindo mais nenhuma pasta específica para ES no âmbito federal.

No âmbito regional, mais enfaticamente no Estado do Pará, a estratégia da ES é desenvolvida por meio da Secretaria de Estado de Assistência Social, Trabalho, Emprego e Renda (SEASTER), a qual promove eventos e oficinas junto a associações, cooperativas e sociedade em geral sobre as ações e importância do desenvolvimento da ES no estado.

Pelo exposto, observa-se que a ES emerge como oportunidade de afirmação econômica e inclusão social principalmente em ambientes distantes da industrialização e do alcance de políticas, como o espaço rural, onde os traços da ES crescem movidos pelos princípios de solidariedade e cooperação, como estratégia de competição no mercado capitalista. Entretanto, recentemente a ES deixou de ter prioridade como política pública, o que compromete a continuidade das ações em curso e exige um maior grau de cooperação e envolvimento dos atores, com a redefinição de papéis e de ações.

A próxima subseção traz a construção do conceito de Agricultura Familiar, uma vez que este estudo se debruçou a compreender o empoderamento das mulheres agricultoras familiares que atuam na FAF UFOPA.

\subsection{A Agricultura Familiar: produção social e econômica}

A categoria agricultura familiar começou a ter visibilidade a partir da redemocratização em 1988, até então os pequenos agricultores não tinham voz e nem oportunidade de participar das ações efetivadas pelas políticas governamentais. Esse panorama desigual no agrário brasileiro teve sua intensificação no período de modernização da agricultura a partir da década de 1960. Nessa época, as políticas creditícias priorizavam os grandes e médios produtores situados nas regiões Sul e Sudeste, os quais atuavam como exportadores (Grisa e Schneider, 2015).

Os pequenos produtores e as regiões distantes dos polos de industrialização ficaram a margem desses investimentos. Contudo, a partir da promulgação da Constituição de 1988 e com o fim do regime militar, ocorre maior abertura de diálogo com o governo, fomentando o protagonismo dos movimentos sociais do campo que reivindicavam a reforma agrária e políticas de acesso ao crédito para os pequenos agricultores 
(Aquino e Schneider, 2015). Para Delgado e Bermasgo (2017) a construção da agricultura familiar no Brasil teve grande participação dos movimentos sociais, inclusive com destaque ao movimento de mulheres.

Uma das grandes conquistas desses movimentos foi o reconhecimento do termo agricultura familiar homologado pelo Decreto de $n^{\circ} 1946$, junho de 1996, que implantou o Programa de Fortalecimento da Agricultura familiar (PRONAF) (Grisa e Schneider, 2015; Aquino e Schneider, 2015).

Visando melhor adequar a política pública aos agricultores familiares, foi instituída a Lei $n^{\circ} 11.326$, de 24 de julho de 2006, visando definir os critérios à classificação do agricultor familiar e dos seus respectivos empreendimentos rurais. Logo, essa lei efetivava o reconhecimento da importância desse segmento produtivo, e, principalmente, fomentava a participação desse setor nas políticas públicas no país.

De acordo com Art. 4 da Lei n 11.326 de julho de 2006 são estabelecidos critérios para a classificação dos agricultores familiares:

\author{
I - não detenha, a qualquer título, área maior do que 4 (quatro) módulos fiscais; \\ II - utilize predominantemente mão-de-obra da própria família nas atividades econômicas \\ do seu estabelecimento ou empreendimento; \\ III - tenha percentual mínimo da renda familiar originada de atividades econômicas do seu \\ estabelecimento ou empreendimento, na forma definida pelo Poder Executivo; (Redação \\ dada pela Lei $n^{\circ} 12.512$, de 2011) \\ IV - Dirija seu estabelecimento ou empreendimento com sua família. (Brasil, 2006, p.1)
}

Diante disso, observa-se que a agricultura familiar é formada por uma diversidade de atores sociais, os quais buscam melhorar as condições econômicas de seu núcleo familiar, mas que priorizam a inclusão e reconhecimento da sociedade em geral. Essa atividade além de ser uma produção social com a predominância do trabalho coletivo familiar, busca aumentar a renda do agricultor rural, possibilitando assim, acesso à cidadania e recursos básicos à sobrevivência. Com isso, além de ser instrumento de disseminação de práticas sustentáveis e políticas públicas, a agricultura familiar é grande fonte de alimentação do mercado interno brasileiro e essencial ao autoconsumo da família, evitando o êxodo rural.

Além disso, estudos apresentados por Sempre Viva (2016) mostra que a agricultura familiar vem contribuindo para autonomia econômica e o reconhecimento da mulher como produtora, isto visto em diversos experiências em feiras de agricultura familiar.

Desta forma, enfatiza-se a importância da discussão de gênero no setor rural, que por anos ficou sobre a sombra do patriarcado, os quais atribuíam apenas o papel de cuidar do lar e filhos. No entanto, de acordo com estudo de Silva e Carneiro (2016) as mulheres estão cada vez mais participando de grupos informais, buscando a complementação da renda familiar e conciliação com o papel de cuidadora do lar e do exercício de atividades domésticas desenvolvidas junto ao seu núcleo familiar, desse modo a próxima subseção apresenta os principais fundamentos da discussão em torno do empoderamento feminino.

\title{
2.30 empoderamento feminino
}

Têm-se utilizado com frequência a palavra empoderamento nos âmbitos profissionais, sociais, acadêmicos, econômico e outros. Baquero (2006) ressalta o surgimento dessa palavra ainda no período da reforma protestante, mas que só foi utilizada fortemente através dos movimentos sociais ocorridos nos Estados Unidos na década de 1990 quando muito se discutia sobre as desigualdades impostas na sociedade, a qual 
tinha a sua frente as manifestações denominadas como novos movimentos sociais, o feminino, os homossexuais e os negros.

Para Baquero (2006) a significância do empoderamento nasce das ações civis, por meio de lutas pelos direitos essenciais de cidadania como a saúde, educação e outros, sendo os resultados observados tanto de forma individual como coletiva. Desse modo, a autora enfatiza essas ações como transformadoras, formadoras de atitudes e pensamentos críticos, ao passo que influenciam diretamente no agir do sujeito, concretizada não apenas quanto ao individual, mas também ao coletivo.

Gohn (2004) destaca que o empoderamento no Brasil não expressa um significado universal, assim, corresponde a dois aspectos: a atuação pró-ativa do coletivo ou grupo, de forma a impulsionar ações desenvolvedoras de autonomia, crescimento social e econômico, ou seja, melhorias na qualidade vida e nas experiências na sociedade. $O$ segundo aspecto está voltado a ações propiciadoras de mudanças positivas na sociedade, como a diminuição das desigualdades, através da inclusão de camadas historicamente marginalizadas ou impostas por suas condições socioeconômicas baixas.

Contudo, Baquero (2006) enfatiza sobre a complexidade do significado desse conceito, podendo ser usado em várias situações. Sendo assim, a autora classificou alguns tipos de empoderamento: o individual, cujo objetivo é a melhoria de vida do indivíduo; o organizacional com foco no aumento da produtividade da empresa; o comunitário relacionado as lutas por direitos e cidadania, as quais podem interferir ou moldar as políticas públicas do país.

O empoderamento no feminismo está intrinsecamente relacionado ao sentido de desenvolver e promover ações para geração de autonomia e igualdades em vários campos. De acordo com a cartilha das Organizações Unidas os princípios do empoderamento feminino em uma visão da participação do mercado de trabalho, no setor privado:

1- Estabelecer liderança corporativa de alto nível para a igualdades de gênero

2- Tratar todos os homens e mulheres de forma justa no trabalho - respeitar e apoiar os direitos humanos e a não discriminação

3- garantir a saúde, a segurança e o bem-estar de todos os trabalhadores e as trabalhadoras;

4- Promover a educação, a formação e o desenvolvimento profissional das mulheres;

5- Implementar o desenvolvimento empresarial e as práticas da cadeia de suprimentos e de marketing que empoderem as mulheres;

6- Promover a igualdade através de iniciativas de defesa comunitária

7- Mediar e publicar os progressos para alcançar a igualdade de gênero (ONU-MULHERES, 2019, p.3)

Dada essa percepção da importância do empoderamento sobre maior participação no mercado de trabalho e de seus princípios, nota-se que esse empoderamento vai além do teórico e na realidade se efetua através de ações proativas e de políticas garantidoras de direitos e inclusão.

Baquero (2006) amplia esse significado do processo de empoderamento, não envolvendo apenas a parte reflexiva ou conceitual, mas um conjunto de aspectos como participação ativa individual e coletiva, incluindo os seguintes aspectos:

1.cognitivo, em que interessa a conscientização sobre a realidade e as causas da dominação;

2. psicológico, ligado ao desenvolvimento de sentimentos de auto-estima e autoconfiança, requisitos para a tomada de decisões; 
3. econômico, que relaciona a importância da execução de atividades que possam gerar uma renda que assegure certo grau de independência econômica;

4. político, que envolve a habilidade para analisar e agir no meio social com vistas a nele produzir mudanças. (Baquero, 2006, p.87)

De acordo com o trecho citado acima, o empoderamento é uma construção do meio psíquico para o econômico e social, admitindo-se a necessidade do desenvolvimento de uma análise crítica da realidade vivenciada e desenvolvimento de sentimentos de autoestima e autoconfiança para alcançar os fatores econômicos e políticos.

No Brasil a contínua luta da mulher em prol de seus direitos é protagonizada em diversas arenas sociais, tanto no âmbito rural, urbano, quanto no profissional ou até mesmo o reconhecimento do seu papel no próprio lar. Andrade (2010) salienta que nas últimas décadas as mulheres estão se organizando em busca de direitos e emancipação financeira, com a finalidade de tornassem protagonistas de sua própria história. Nessa luta, a autora argumenta a importância das feiras livres para a construção do empoderamento feminino, relatando que apesar de executar trabalhos domésticos e da feira, as mulheres se sentem reconhecidas tanto no âmbito de seu lar como na sociedade. A autora relata o aumento do poder de decisão da mulher no lar sobre a educação dos filhos e investimentos da renda familiar.

Outro fator é a contribuição da renda gerada pela feira no orçamento familiar, porém, a pesquisa mostra a desigualdade em termos salariais, sendo o cônjuge e pai portador de salários superiores.

No estudo de Anacleto, Coelho e Curvelo (2016) apresentam-se resultados sobre a atuação da mulher nas feiras de agricultura. Assim, $85 \%$ das mulheres entrevistadas relataram o aproveitamento do conhecimento em alguma atividade, ou até mesmo a habilidade comunicativa para comercializar produtos na feira. Essa pesquisa mostrou também, a predominância das mulheres nas feiras e o núcleo familiar como fator motivacional, principalmente, seus filhos.

Ainda nesse estudo relata-se que $63 \%$ das mulheres tem a feira como única fonte de renda, enquanto as demais exercem outras atividades em horários vagos, como atividades na agricultura ou em serviços domésticos. Por outro lado, o seminário "Gênero e Mercados Inclusivos" ocorrido em São Paulo no ano de 2016, apresentou a vivência de grupos femininos na luta pela construção de autonomia e comercialização dos seus produtos. Nesse evento, mostrou-se, de forma geral, a mulher sendo pouca valorizada no seu trabalho no campo ou até mesmo imperceptível, aparecendo apenas como ajudante do cônjuge (Sempre Viva, 2016).

Além disso, o seminário mostrou alguns casos em que a mulher relata o início da produção e comercialização ainda pequenas. Porém, quando crescem e se tornam prósperas, os homens tendem a apropriar-se do negócio. Outro fator identificado nessa discussão foi a questão da divisão do tempo, pois verificou-se a má distribuição de tarefas ao longo do dia, sobrecarregando apenas a mulher (Sempre Viva, 2016).

As experiências das feiras de reforma agrária em Alagoas são reconhecidas por suas participantes, mulheres do Movimento de Sem Terra (MST), como espaços participativos de trocas de experiências e fortalecimento, além de possibilitar a inclusão social e econômica. Neste sentido, os princípios da ES são elementos essenciais na busca de alternativas para mitigar essas desigualdades de gênero e por direitos e emancipação econômica, através de empreendimentos solidários promotores de igualdade e espaços democráticos, os quais contribuem para o acesso de direitos e propiciam o desenvolvimento local.

\section{Resultados e discussão}


Neste capítulo serão apresentados os resultados da pesquisa sobre o empoderamento das mulheres agricultoras na FAF-UFOPA. O mesmo está organizado em três partes. A primeira subseção abordará a contextualização da Incubadora de Empreendimentos solidários da UFOPA e suas atividades da feira, na segunda será apresentada a caracterização das mulheres que comercializam na feira e por último serão expostos às conquistas e os desafios enfrentados pelas mulheres na FAF - UFOPA.

\subsection{Contextualização da Incubadora de Empreendimentos Solidários da UFOPA e suas atividades da Feria da Agricultura Familiar}

O Projeto de Extensão "Incubadora de Empreendimentos Solidários (IES) ", vinculado à Universidade Federal do Oeste do Pará (UFOPA), que fica situada no município de Santarém, Estado do Pará, possui aproximadamente 304.589 habitantes no ano de 2019, o sexto maior Produto Interno Bruto (PIB) do Estado, seu o Índice de Desenvolvimento Humano Municipal (IDHM) 0,691, considerado médio desenvolvimento, e também é considerada cidade polo da mesorregião Baixo Amazonas, segundo o IBGE (2019).

A Incubadora de Empreendimentos Solidários IES-UFOPA teve sua origem no ano de 2013, buscando a construção da autogestão em Empreendimentos Econômicos e Solidários (EES) essencialmente na zona rural, seguindo os princípios da Economia Solidária (ES) - cooperação, solidariedade, autogestão e viabilidade social e econômica. Isso porque, considera-se fundamental para o sucesso destes empreendimentos que esses princípios sejam fortalecidos, uma vez que, são movidos pela participação democrática, colocando-os em condições iguais e deixando um horizonte desejável para realizações das ações no âmbito da extensão. $O$ intuito desses EES é fortalece as unidades familiares que os formam, reduzindo o êxodo rural e seus diversos impactos negativos para a sociedade.

As ações da IES UFOPA pautam-se na transferência de tecnologias sociais, por meio de cursos e oficinas, para que integrem de forma ampla e interdisciplinarmente, o ensino, a pesquisa e a extensão. As principais iniciativas promovidas pela IES desde a sua implementação foram: Assessoramento na construção do Planejamento Estratégico da Cooperativa da Agricultura Familiar de Mojuí dos Campos (COOFAM); Cursos diversos de contabilidade, informática, economia solidária e planejamento oferecidos a diversas organizações da agricultura familiar; Implantação da Feira da Agricultura Familiar na UFOPA (FAF); Planejamento Estratégico da Associação das Mulheres Trabalhadoras Rurais do Município de Belterra (AMABELA); Planejamento estratégico da FAF UFOPA; Parceria técnica com a Emater na Feira do Orgânico

Dado a grande notoriedade e alcance conquistados pela Feira da Agricultura Familiar dentro da Incubadora, esta foi eleita para ser objeto de investigação e análise do presente estudo. A FAF- UFOPA iniciou suas atividades no ano de 2016, no auditório da UFOPA no Campus Amazônia. Inicialmente, as edições da FAF - UFOPA aconteciam uma vez por mês. O público frequentador na época era de aproximadamente 120 pessoas/feira. A partir de 2017 a FAF-UFOPA passou ocorrer semanalmente, ao todo foram realizadas 42 feiras nesse ano, com a média de público por volta de 100 pessoas por feira. Com a assessoria da IES ocorreram oficinas de Economia Solidária e Comércio Justo e Solidário, com a perspectiva de orientar e capacitar os produtores (Silva, 2019).

No ano de 2018 o planejamento se aperfeiçoou ainda mais, isso pode ser visto com a execução de feiras temáticas como a do dia internacional da mulher, das mães, e outras temáticas. Desde sua implantação até o ano de 2018 foram efetuadas 92 feiras, assim totalizando uma receita de $R \$ 156.295,53$, com a participação efetiva de 48 produtores. 
Conforme os dados de faturamento dos relatórios da FAF-UFOPA contidos no trabalho de Silva (2019) observou-se que a feira teve expressivo crescimento em sua comercialização no decorrer desses anos. Com o aumento da frequência das atividades da Feira, que passou a ser semanal a partir do ano de 2017, ele continuou crescendo. No ano de 2018 continuou a tendência de comercialização ascendente, o que significa que a Feira já possui um público fidelizado e continua conquistando novos consumidores.

Silva (2019) afirma que desde sua implantação, a FAF-UFOPA tinha como participantes a Cooperativa da Agricultura Familiar de Mojuí dos Campos (COOFAM), a Associação Tapajós Orgânico (ATO), a Associação de Mulheres de Belterra (AMABELA) e a Cooperativa Mista Agroextrativista do Tapajós (COOMAPLAS). No recente Relatório da Incubadora de Empreendimentos Solidários (2019) foram incluídas como participante o Sindicato de Trabalhadores e Trabalhadoras Rurais de Santarém, Associação de Mulheres Trabalhadoras do município de Santarém e Associação dos Produtores Rurais de Santarém.

\subsection{Caracterização do perfil socioeconômico das agricultoras - FAF}

Buscando compreender a dinâmica social, econômica e familiar que estas mulheres estão inseridas, e de que forma esses fatores contribuem ou não para a constituição do seu empoderamento, apresentaremos o perfil socioeconômico das mulheres agricultoras da FAF - UFOPA. Para isso, é importante destacar a percepção da mulher sobre ela mesma. Assim, todas as entrevistadas se intitularam agricultoras, que cumprem o papel de esposa e mãe, com idades entre 34 a 56 anos.

A idade das agricultoras permite observar a maturidade de experiências tanto no âmbito familiar, como na produção, possibilitando maior carga de conhecimento sobre o trabalho produtivo. Sendo assim, a idade mais avançada implica em uma responsabilidade familiar maior, além de demonstrarem o gosto pela atividade, e satisfação de poder ajudar na manutenção do seu núcleo familiar.

Os resultados da pesquisa apontam $56 \%$ das agricultoras da FAF com nível de escolaridade de Ensino Médio Completo, todavia, existe um percentual representativo de $33 \%$ destas que não alcançaram essa formação básica, também foi possível identificar que as agricultoras possuem nível de escolaridade baixo, visto que $44 \%$ não conseguiram concluir o ensino médio. De acordo com a experiência das feiras livres no litoral de Paraná exposto por Anacleto, Coelho e Curvelo (2016) destacaram a possibilidade do nível de escolaridade e da idade serem um dos motivos para a entrada da mulher nesse setor de comercialização.

Os dados da pesquisa revelam que todas as agricultoras possuem núcleo familiar formado por marido ou companheiro e que $55 \%$ destas possuem o quantitativo de dois a seis filhos, ou seja, o número de pessoas que residem em cada residência está entre duas a oito pessoas. É importante compreender essa formação familiar para relacionar com o fator produção, renda e motivação para comercialização na feira.

Ademais, é importante o envolvimento dos membros da família na produção, assim evitando concentração de trabalho, ou mesmo, como fator relevante para continuidade ao ciclo da agricultura familiar, dessa forma repassando os conhecimentos para a próxima geração e possibilitando a continuidade da produção de alimentos mais saudável e de forma sustentável.

Em decorrência disso, buscamos apresentar o percentual de colaboração dos componentes familiares na produção. Nesse aspecto, a pesquisa identificou que $44,4 \%$ das agricultoras entrevistadas produzem em terreno próprio, 33,3 \% são assentadas e os demais utilizam terreno arrendado ou de posseiro.

A comercialização dos produtos das agricultoras na FAF - UFOPA estão distribuídos como demonstrados no quadro 1: 
Quadro 1 - Tipo de produção desenvolvida pelas agricultoras da FAF - UFOPA

\begin{tabular}{|l|l|}
\hline TIPO DE PRODUÇÃO & \multicolumn{1}{|c|}{ PRODUTOS } \\
\hline Artesanal & Pano de prato \\
\hline Frutas & $\begin{array}{l}\text { Manga, limão, banana, feijão, tapioca mamão, pupunha, abacate, } \\
\text { castanha do Brasil, sapotilha, laranja, tucumã . }\end{array}$ \\
\hline Hortaliças e tubérculos & $\begin{array}{l}\text { Alface, couve, rúcula, cheiro-verde, salsa, berinjela, açafrão, } \\
\text { macaxeira, batata doce, araça boi, gengibre. }\end{array}$ \\
\hline Produtos processados & $\begin{array}{l}\text { Doce, biscoito, tapioca, polpa, tempero, café, xarope, óleo de coco, } \\
\text { suco de açaí, tapioquinha, pé de moleque, bolo, salgados, } \\
\text { pimenta. }\end{array}$ \\
\hline Outros & $\begin{array}{l}\text { Plantas medicinais, galinha caipira, ovos, amendoim, artesanato } \\
\text { indígena. }\end{array}$ \\
\hline
\end{tabular}

Fonte: Elaborado pelos autores (2020)

De acordo com os produtos identificados na pesquisa, torna-se possível concordar com o estudo de Pinto (2010), onde argumenta que a mulher utiliza de seus conhecimentos adquiridos ao longo de sua vida para obter renda extra, como é o caso dos conhecimentos na gastronomia ou mesmo os conhecimentos tradicionais passados de geração a geração.

Nesse levantamento, observou-se que a maioria das agricultoras comercializam diferentes tipos de produtos e não apenas os produtos oriundos da produção agrícola. Sendo assim, a renda obtida em média em cada feira corresponde a seguinte distribuição: $22,2 \%$ das agricultoras ganham menos de 100 reais, $33,3 \%$ ganha acima de 300 reais e $44,4 \%$ ganham em média de 100 a 200 reais semanalmente.

Em relação a faixa de renda mensal das agricultoras os dados da pesquisa revelam que uma parte das entrevistadas possuem renda abaixo de um salário mínimo, a distribuição dos dados se configurou da seguinte forma: $44,44 \%$ possuem renda menor que um salário; $33,33 \%$ possuem renda de um salário; apenas $22,22 \%$ possuem renda maior que um salário.

Quando questionada a fonte dessa renda, as entrevistadas responderam que também comercializam em outras feiras livres no município de Santarém ou em outros canais de comercialização, como: Feira do Mercadão; Feira do Produtor Rural; Feira do Aeroporto Velho; Feira da Empresa de Assistência Técnica e Extensão Rural; Feira de Alter-do-Chão; Cristo Rei; Atravessadores; Comunidades. Além disso, a renda dessas agricultoras em alguns casos é complementada com benefício social da Bolsa Família ou benefício de aposentadoria.

Além do papel de agricultora e comerciante de produtos na FAF - UFOPA, as mulheres exercem as atividades em seu lar e assim dividem o tempo em produzir, comercializar, cuidar da família e atividades domésticas.

De acordo com o levantamento dos dados da divisão do tempo da agricultora em suas atividades diárias verificou-se que ocorre um grande volume de horas trabalhadas diariamente pelas agricultoras, isto quando se soma o tempo médio no lar e o trabalhado no roçado. No caso da primeira e oitava entrevistada as horas de permanência no roçado chegam a alcançar de 10 a 12 horas por dia.

Conforme relatos no seminário da Sempre Viva (2016) a mulher ainda ocupa uma divisão desigual nas tarefas diárias, isso inclui trabalhos domésticos e no campo, assim em muitos casos, a mulher apresenta sobrecarga de atividades, dado isso, cabe destacar se as mulheres estão obtendo ajuda dos outros membros da família nessa atividade

Os resultados demostraram que a grande parte das agricultoras são ajudadas por seus cônjuges e filhos, porém ainda há um percentual significativo de mulheres que realizam atividades domésticas do lar sem ajuda nenhuma, assim ocorrendo a sobrecarga de trabalhos. O percentual se distribuiu da seguinte forma: $33,33 \%$ trabalham sozinhas nas atividades do lar; $33,33 \%$ recebem ajuda do marido e dos filhos para 
desenvolver as tarefas; $22,22 \%$ recebem ajuda somente dos filhos, e; $11,11 \%$ recebem ajuda somente de seus maridos.

Portanto, de acordo com os resultados descritos nesse capítulo, constatou-se que a mulher exercer grande participação na renda familiar, como também na produção da agricultura familiar e nas atividades domésticas. No entanto, ainda se verifica que a feira é um meio flexível de prover renda e ajudar o seu núcleo familiar, no qual desenvolvem multitarefas e que transformaram seus conhecimentos adquiridos ao longo de suas vidas em produto para sua subsistência.

\subsection{Principais conquistas e desafios}

Esta etapa busca expor as principais conquistas e desafios, os quais estão impactando no empoderamento das agricultoras, especialmente, após sua entrada na Feira de Agricultura Familiar da UFOPA. Neste panorama serão descritas as opiniões das agricultoras em relação aos fatores positivos e negativos de comercializar na feira, o nível de satisfação, o que mudou com o ingresso das agricultoras na feira e suas respectivas motivações para sua entrada nesse meio de comercialização.

De acordo com a pesquisa, as agricultoras entrevistadas responderam de forma positiva sua satisfação, sendo que $100 \%$ estão satisfeitas em comercializar na feira, como forma de expressar elas completam dizendo: "espera que dure bastante tempo" (entrevistada 01), ou mesmo que " não vem mais vezes, por falta de tempo" (entrevistada 09), outra agricultora afirmou " não pensa em sair" (entrevistada 08), outro argumento foi a "grande oportunidade para desenvolver e vender seus produtos" (entrevistada 07), e ainda citaram "a convivência com as outras feirantes e consumidores" ( entrevistada 03).

A partir dessas opiniões das produtoras da FAF - UFOPA percebe-se a grande satisfação de trabalhar na feira e ainda sua perspectiva de continuidade na atividade. Dito isso, ocorre a necessidade de destacar os fatores positivos elencados pelas agricultoras em suas experiências dos últimos anos na FAF - UFOPA.

A categoria renda mensal corresponde a $20 \%$ dos fatores citados nas respostas das agricultoras, de acordo com estas, a feira proporciona ganhos financeiros, além disso destacaram como ponto positivo a comercialização dos produtos com $13,3 \%$, pois em alguns casos estavam estragando seus produtos ou então não havia espaço para vender. Outro ponto positivo foi a questão do horário flexível, presente em $13,3 \%$ das falas das agricultoras, ressaltando que no tópico anterior foi destacado a flexibilidade de tempo, por estas possuírem diversas funções ao longo do dia.

É importante notar a satisfação das agricultoras em participar da FAF - UFOPA, onde possibilita realizar trocas de conhecimento e ainda manter a aproximação com os frequentadores da feira, demonstrando o sentimento de reconhecimento da importância do seu trabalho como agricultora através do incentivo a feira e boa recepção do público acadêmico são confirmadas por meio da categoria acolhimento da universidade com o percentual de frequência de $13,33 \%$.

Outros aspectos relevantes também são a aceitação do preço dos produtos da feira, sem ocorrer à pechincha, ou seja, os consumidores veem a comercialização com preço justo. A questão de ambiente, também foi destacada pelas agricultoras como fator positivo a limpeza da estrutura com cerca de $6,67 \%$. A disponibilidade de transporte também foi vista como positivo com $6,67 \%$ de frequência no discurso das agricultoras, porém, verificamos nos dados a seguir que as dificuldades com o transporte como um fator que pode comprometer a frequência da agricultora na feira.

As produtoras da FAF-UFOPA assinalam alguns pontos negativos que dificultam a comercialização das feirantes na FAF - UFOPA. Verificou-se que o ponto negativo de maior significância é a dificuldade com transporte em $40 \%$ de frequência nas falas das agricultoras, $30 \%$ não apontaram nenhuma dificuldade. Além 
disso, grande dificuldade das agricultoras para produção está em relação a ausência de recurso financeiros com $25 \%$ frequente nas falas destas, $25 \%$ citaram a falta de assistência técnica, e 16,6\% responderam não haver nenhuma dificuldade para produzir. Os demais fatores de dificuldade fazem parte do risco da sua atividade, como fatores climáticos, a absorção do mercado, pragas, ou mesmo a falta de água.

Apesar dessas dificuldades existentes e dos riscos que a atividade oferece, as agricultoras continuam participando da FAF-UFOPA, uma vez questionadas sobre sua motivação para a comercialização na FAF - UFOPA, responderam da seguinte forma: $33,3 \%$, participação em associação; $22,2 \%$, gosto pela atividade; $22,2 \%$, necessidade de fonte de renda e comercializar os produtos; $11,1 \%$ a perda do produto, e; $11,1 \%$ a proposta.

Torna-se notável a importância da associação na vida dessas mulheres agricultoras, pois cerca de $33,3 \%$ responderam que foram motivadas pela Associação em que fazem parte, desta forma incentivando a produzir e se inserir no mercado, buscando auferir renda, a inclusão social e também diminuir as desigualdades de gêneros. Além de ser uma forma de emancipar economicamente e socialmente a mulher.

Além disso, verifica-se que as agricultoras gostam de exercer a atividade e não estão apenas pela renda, isto constatado pela frequência de $22,2 \%$ na fala destas. Outros fatores motivacionais destacaram-se em menores percentuais, como propostas/convite por terceiros e a perda do produto.

Com isso, através da aplicação dos questionários, pode-se identificar algumas mudanças positivas na direção da constituição do empoderamento social e econômico da mulher feirante.

Tabela 1: Mudanças na vida das feirantes com a entrada na FAF - UFOPA

\begin{tabular}{ll}
\hline Mudança após participação na FAF-UFOPA & Percentual \\
\hline Aumento da renda & $46,15 \%$ \\
Autonomia & $15,38 \%$ \\
Aumentos da confiança em desenvolver a atividade & $15,38 \%$ \\
Independência & $7,69 \%$ \\
Oportunidade da mulher produzir e vender & $7,69 \%$ \\
Novos conhecimentos & $7,69 \%$ \\
\hline
\end{tabular}

Fonte: Elaborado pelos autores, 2020.

De acordo com a pesquisa evidencia-se a grande representatividade do aumento da renda para estas mulheres, ou seja, a partir de sua participação ocorreram melhorias significativas no seu orçamento mensal e familiar. De acordo com o estudo de Andrade21 a participação da mulher no orçamento familiar possibilita obter maior poder de decisão no lar, maior ajuda no ambiente doméstico e também sobre a decisão dos investimentos da renda familiar.

Nota-se também que esses resultados advindos da participação da FAF - UFOPA contribuíram para a autonomia dessas mulheres, isto foi frequente em $15,38 \%$ nos seus discursos, outro fator citado foi o aumento da confiança em desenvolver tal atividade com 15,38\% de frequência nas falas. Deste modo, estes resultados são de grande relevância para notar que a FAF - UFOPA tem contribuído na vida dessas agricultoras, tanto com os aspectos financeiros, quanto para o fortalecimento de sentimentos de confiança, autonomia, independência.

Logo, Baquero (2006) enfatiza que a construção do empoderamento feminino é constituído do aspecto cognitivo, psicológico, econômico e político. No estudo de caso da FAF-UFOPA, observa-se que as mulheres estão cada vez mais fortalecendo o aspecto psicológico, aumentando a confiança em comercializar e tomar decisões; no econômico, observa-se que as agriculturas reconhecem a importância de sua atividade como geradora de renda e suporte para o seu núcleo familiar. 
Nas falas das agricultoras V.N; S.C; I.S é possível verificar o sentimento de gratidão tanto pelo projeto, quanto pela Associação em que participa, ou seja, as agricultoras compreendem a importância dessa atividade no seu meio social e sua pró-atividade de executar tais tarefas semanais, mostram a disposição de produzir mudanças na sua realidade.

\section{Considerações finais}

A FAF-UFOPA é baseada nos preceitos da ES, que pressupõem a solidariedade, a igualdade, aspectos democráticos e de autogestão, que buscam contribuir com as camadas desfavorecidas pelo sistema de produção capitalista., oportunizando melhorias financeiras e sociais, que possibilitem manter seu bem-estar e acessos à direitos básicos.

O presente estudo sugere uma elevada importância da FAF-UFOPA como espaço de inclusão social e econômica das mulheres-agricultoras da região metropolitana de Santarém, onde permite a comercialização de produtos advindos da agricultura familiar, produção artesanal e entre outros. Além disso, proporciona a troca de conhecimentos entre as agricultoras e ampliação de redes de relacionamento.

Respondendo a problemática do trabalho, por meio dos dados levantados na pesquisa em dezembro de 2018, a FAF - UFOPA impacta positivamente a vida das agricultoras, tanto na emancipação econômica através da oportunidade de comercialização, como também através do fortalecimento da confiança, autoestima, compreendendo a importância do seu papel tanto para sua família, como também para conquista da independência financeira e autonomia, além dos novos conhecimentos obtidos nesse meio.

Desta forma, pode se afirmar que FAF- UFOPA está contribuindo diretamente para a construção desse empoderamento das agricultoras, e que apesar das dificuldades enfrentadas pelo transporte ou riscos das atividades, as mesmas se sentem satisfeitas com os resultados obtidos, com expectativa de continuar futuramente. Contudo, ainda se observa que as agricultoras ainda sofrem desigualdades com a divisão do tempo, havendo assim a sobrecarga de atividades.

As atividades da FAF-UFOPA, disponibilizaram um canal de comercialização para produtos da agricultura familiar em Santarém, além de dar suporte para o pequeno agricultor, suas associações e cooperativas, propiciando o acesso à alimentos mais saudáveis e assim fortalecendo a agricultura familiar da região metropolitana de Santarém e garantindo a segurança alimentar da comunidade acadêmica.

Desde o ano de implantação até o ano de 2018, a feira obteve grandes resultados, como o aumento considerável do faturamento anual, isso justifica-se pelo aumento da frequência das atividades que passaram de mensal para semanal, demonstrando assim que no decorrer desses anos a FAF-UFOPA vem conquistando a fidelização da comunidade local.

Em relação ao perfil socioeconômico das mulheres que comercializam na FAF - UFOPA, possuem idade entre 34 a 56 anos e apenas $56 \%$ concluíram o ensino médio completo. No que concerne a renda $44,44 \%$ possuem mais que um salário mínimo, $33,33 \%$ apenas um salário mínimo e o restante do percentual tem renda abaixo de um salário.

Constatou-se que todas as agricultoras recebem ajuda de seus familiares na produção dos seus produtos. Entretanto, nas atividades domésticas do lar não ocorre essa frequência, pois ainda persisti um pequeno percentual de mulheres que realizam essas atividades sozinhas.

As principais conquistas das agricultoras estão em relação ao seu aumento da renda mensal, e com isso maior possibilidade de ajuda para manutenção dos membros da família, a oportunidade de ter um espaço 
para comercializar os seus produtos, um novo canal de comunicação, o aumento da confiança em desenvolver a atividade e maior autonomia econômica.

A concentração de mulheres na FAF-UFOPA, permite mostrar a vontade de transformação da sua realidade, melhor organização e simultaneamente o seu protagonismo na agricultura familiar e permite a inclusão mercadológica e conquista cada vez mais espaço nesse mercado tão desigual. Já que muitas das vezes o trabalho da mulher no meio rural não é considerado como produtivo, é dado apenas como ajuda ao seu marido. Logo, além da questão financeira, ocorre paralelamente a busca do reconhecimento tanto no setor, como em seu próprio lar.

A luta pela a construção do empoderamento, requer o fortalecimento desde os aspectos psicológicos como os econômicos, políticos e outros. Desta forma, a feira proporciona ferramentas para o alcance desse empoderamento, porém existem ainda aspectos complexos, como a parte psicológica ou cognitiva, que podem dificultar o empoderamento, que algumas vezes pode se dá apenas superficialmente, com o aferimento de renda individual, porém, não realiza uma análise crítica da desigual e dominação existente na sociedade ou em seu próprio lar.

A luta é constante e gradativa para o empoderamento das agricultoras, mas percebe-se grande avanço, e que o âmbito da universidade e do projeto favorecem esse desenvolvimento. Neste sentido, o empreendimento solidário cumpre esse aspecto de transmitir os pressupostos de igualdade, solidariedade, democracia e autogestão.

Com isso compreendemos que a Economia Solidária protagonizada na FAF - UFOPA tem se constituído em uma alternativa concreta de mitigação as desigualdades socioeconômicas e de gênero, oportunizando uma arena de troca de conhecimentos, experiências, mas também uma troca econômica.

Assim sendo, esta monografia se debruçou a investigar esse mundo das mulheres agricultoras, mães, esposas, feirante, considerando a sua importância para o aprofundamento do estudo de desigualdades de gênero, sobre o empoderamento feminino, o seu protagonismo na agricultura familiar, principalmente em país com grandes índices de desigualdades e ainda mais com o Estado do Pará sendo um dos últimos no ranking dos índices de desenvolvimento humano.

Por ser um estudo inovador é um grande passo para essa área, que ainda é pouco investigada na região amazônica, dito isso, espera-se que haja uma continuidade de produção científica que busquem mostrar essas experiências e seu impacto na sociedade, como forma de luta contra desigualdades e a busca desse empoderamento.

\section{Referências:}

Aquino, J. R.; Schneider, S. (2015). O Pronaf e o desenvolvimento rural brasileiro: avanços, contradições e desafios para o futuro. In: GRISA, Catia; SCHNEIDER, Sergio (org). Políticas públicas de desenvolvimento rural sustentável no Brasil. Porto Alegre- Ed. UFRGS, p. 53-77. Disponível em: http://www.ufrgs.br/pgdr/publicacoes/livros/outras-publicacoes/politicas-publicas-de-desenvolvimento-ruralno-brasil. Acesso em: 26 de out, 2019.

Aleixo, A. S. M. D. F. (2014). Da Economia Social para a Economia Solidária. 100 f. Dissertação (Mestrado) - Escola de Ciências Sociais e Humanas, Departamento de Economia Política, Instituto Universitário de Lisboa, Lisboa. Disponível em https://repositorio.iscte-iul.pt/handle/10071/11388. Acesso: 29 nov, 2019. 
Anacleto, A.; Coelho, A. Pedro; Curvelo, Eder Bruno Couto. (2016). As Mulheres empreendedoras e as feiras livres no Litoral do Paraná. Revista Faz Ciência FC, Francisco Beltrão, vol. 18, n. 27, p. 118-139. Disponível em: http://e-revista.unioeste.br/index.php/fazciencia/article/view/1277. Acesso em: 25 de nov. 2019.

Andrade, F. J. R. (2010). O empoderamento da mulher: um estudo empírico da feira do produtor de Toledo/PR. 99 f. Dissertação (Mestrado) - Mestrado em Desenvolvimento Regional e do Agronegócio, Universidade Estadual do Oeste do Paraná, Toledo. Disponível em : http://tede.unioeste.br/handle/tede/2267. Acesso em:20 de Nov. de 2019.

Baquero, R. V. A. (2006). Empoderamento: questões conceituais e metodológicas. Redes: Revista do desenvolvimento Regional, Santa Cruz do Sul, vol. 11, n. 2, p. 77-93. Disponível em: https://online.unisc.br/seer/index.php/redes/article/view/10843/pdf. Acesso em 6 de novembro de 2019.

Brasil (2006). Lei $n^{\circ}$ 11.326. Estabelece as diretrizes para a formulação da Política Nacional da Agricultura Familiar e Empreendimentos Familiares Rurais. Diário Oficial da União. Brasília, DF. Disponível em: http://www.planalto.gov.br/ccivil_03/_ato 20042006/2006/lei/111362.htm. Acesso em: 25 de out de 2019.

Cattani, A. D et al. (2009). Dicionário Internacional da outra economia. Biblioteca Nacional de Portugal.

Delgado, G. C.; Bermasgo, S. M. P. P. (2017). Agricultura familiar brasileira: desafios e perspectivas de futuro. Brasília: Ministério do Desenvolvimento Agrário. Disponível em: http://www4.planalto.gov.br/consea/publicacoes/agricultura/agricultura-familiar-brasileira-desafios-eperspectivas-do-futuro/1-agricultura-familiar-brasileira-desafios-e-perspectivas-do-futuro.pdf . Acesso em: 26 de out, 2019.

Fórum Brasileiro de Economia Solidária - FBES (2005). Carta de princípios da Economia Solidária. Disponível em: https://fbes.org.br/2005/05/02/carta-de-principios-da-economia-solidaria/. Acesso em: 04 de set, 2019.

França-Filho, G. C. (2007). Teoria e prática em economia solidária: problemática, desafios e vocação. In: Civitas - Revista de Ciências Sociais, v. 7, n.1. Disponível em: http://revistaseletronicas.pucrs.br/ojs/index.php/civitas/article/view/2041. Acesso em: 03 de setembro de 2019.

Gohn, M. da G. (2004). Empoderamento e participação da comunidade em políticas sociais. Saúde e Sociedade v.13, n. 2, p. 20-31. Disponivel em: http://scielo.br/scielo.php?pid=S010412902004000200003\&script=sci_abstract\&tIng=pt. Acesso em 23 de agosto de 2019.

Grisa, C; Schneider, S. (2015) Três gerações de políticas públicas para a agricultura familiar e formas de interação entre sociedade e Estado no Brasil. In: GRISA, Catia; SCHNEIDER, Sergio (org). Políticas públicas de desenvolvimento rural sustentável no Brasil. Porto Alegre- Ed. UFRGS. Disponível em: http://www.ufrgs.br/pgdr/publicacoes/livros/outras-publicacoes/politicas-publicas-de-desenvolvimento-ruralno-brasil. Acesso em: 26 de out, 2019.

Instituto Brasileiro de Geografia e Estatística (2019). Cidades. Disponível em: https://cidades.ibge.gov.br/brasil/pa/santarem/panorama. Acesso em: 10 de nov, de 2019.

Ministério do Trabalho e Emprego/ Secretaria Nacional de Economia Solidária - TEM/SENAES. (2010). Conceitos de economia solidária. In: Economia solidária: caderno pedagógico educandas e educandos, Brasília. http://portal.mec.gov.br/index.php?option=com_docman\&view=download\&alias=6013-caderno4-educandoeconomia-solidaria\&ltemid=30192. Acesso em: 20 de out. 2019.

Nagem, F. A; De Jesus, S. A. (2013). V Plenária Nacional de Economia Solidária: trajetória e construção da economia solidária no Brasil, IPEA: Brasília. Disponível em: 
http://repositorio.ipea.gov.br/bitstream/11058/3868/1/bmt54_econ03_vplenaria.pdf. Acesso em: 20 de out de 2019

Organização das Nações Unidades - ONUMULHERES. (2019). Princípios de empoderamento das mulheres. Disponível

em: http://www.onumulheres.org.br/wpcontent/uploads/2016/04/cartilha_ONU_Mulheres_Nov2017_digital.pdf. Acesso em: 10 de nov,2019.

Pinto, C. R. J. (2010). Feminismo, história e poder. In: Dossiê. Rev. Sociol. Polít., Curitiba, v. 18, n. 36, p. 15-23. Disponível em: http://www.scielo.br/pdf/rsocp/v18n36/03.pdf. Acesso em: 20 de nov. de 2019.

Santos, V. V. (2010). Economia Solidária: principais conceitos e a materialidade na realidade brasileira. UFPA. Dissertação apresentada ao Núcleo de Altos Estudos Amazônicos da Universidade Federal do Pará Programa de Pós-Graduação em Desenvolvimento Sustentável do Trópico Úmido, Belém, 2010. Disponível em: https://sigaa.ufpa.br/sigaa/public/programa/defesas.jsf?lc=lc=pt_BR\&id=473. Acesso em: 10 de nov,2019.

Sempre Viva (2016). Mulheres do campo construindo autonomia: Experiências de comercialização. São Paulo. Disponível em: http://www.sof.org.br/wp-content/uploads/2016/03/Mulheres-do-campo-web-1.pdf. Acesso em: 02 de setembro de 2019.

Silva, S. P.; Carneiro, L. M. (2016). Os novos dados do mapeamento de economia solidária no Brasil: Nota metodológica e análise das dimensões socioestruturais dos empreendimentos. Relatório de Pesquisa do IPEA.

Disponível em:<http://repositorio.ipea.gov.br/bitstream/11058/7410/1/RP_Os\%20Novos\%20dados\%20do\%20mapea mento\%20de\%20economia\%20solid\%C3\%A1ria\%20no\%20Brasil_2016.pdf. Acesso em: 10 de nov,2019.

Silva, S. P. (2018). Crise de paradigma? a política nacional de economia solidária no PPA 2016-2019 .IPEAMercado de Trabalho. Disponível em: http://repositorio.ipea.gov.br/bitstream/11058/8393/1/bmt_64_crise.pdf. Acesso em: 10 de nov, 2019.

Silva, D. C. C. (2019). O comércio justo e solidário: um estudo sobre a Feira da Agricultura Familiar da UFOPA. 58f. Trabalho de Conclusão de Curso de graduação em ciências econômicas, Universidade Federal do Oeste do Pará - UFOPA, Santarém.

Singer, P. (2002a). Introdução à Economia Solidária. 1ª ed. São Paulo: Editora Fundação Perseu Abramo.

Singer, P. (2002b). A recente ressurreição da economia solidária no Brasil. In: Boaventura de Sousa Santos (org.), Produzir para viver: os caminhos da produção não capitalista. Rio de janeiro: Civilização Brasileira. 